\title{
Moxibustion for Chronic Fatigue Syndrome: A Systematic Review and Meta-Analysis
}

\author{
Jianyu You $\mathbb{D},{ }^{1}$ Jing Ye, ${ }^{1}$ Haiyan $L i \mathbb{D},{ }^{1}$ Wenguo Ye $\mathbb{D},{ }^{2}$ and Ensi Hong $\mathbb{D}^{1,2}$ \\ ${ }^{1}$ Jiangxi University of Chinese Medicine, Nanchang, China \\ ${ }^{2}$ The Affiliated Hospital of Jiangxi University of Chinese Medicine, Nanchang, China \\ Correspondence should be addressed to Wenguo Ye; 648957697@qq.com and Ensi Hong; 2224901965@qq.com
}

Received 20 August 2021; Revised 19 October 2021; Accepted 22 October 2021; Published 11 November 2021

Academic Editor: Gerhard Litscher

Copyright (c) 2021 Jianyu You et al. This is an open access article distributed under the Creative Commons Attribution License, which permits unrestricted use, distribution, and reproduction in any medium, provided the original work is properly cited.

Objective. This review aimed at systematically evaluating the efficacy and safety of moxibustion for chronic fatigue syndrome (CFS). Methods. Relevant trials were searched in seven digital databases up to January 2021. After literature screening, data extraction, and literature quality evaluation, the included studies were meta-analyzed using RevMan 5.4 software. The evidence level was assessed using the Grading of Recommendations, Assessment, Development, and Evaluation (GRADE). Results. Fifteen studies involving 1030 CFS participants were included. Meta-analyses showed a favorable effect of moxibustion on the total effective rate compared with acupuncture $(\mathrm{OR}=4.58,95 \% \mathrm{CI}=[2.85,7.35], P<0.00001)$ and drugs $(\mathrm{OR}=6.36,95 \% \mathrm{CI}=[3.48$, 11.59], $P<0.00001)$. Moxibustion also appeared to significantly reduce fatigue severity measured by fatigue scale-14 (FS-14) $(\mathrm{WMD}=-2.20,95 \% \mathrm{CI}=[-3.16,-1.24], P<0.00001)$ and fatigue assessment instrument $(\mathrm{FAI})(\mathrm{WMD}=-16.36,95 \% \mathrm{CI}=$ $[-26.58,-6.14], P=0.002)$ compared with the control group. In addition, among the 15 included studies, only two studies reported adverse events related to moxibustion, and the symptoms were relatively mild. The quality of evidence based on the 15 included trials was assessed as moderate to very low. Conclusions. Based on limited evidence, moxibustion might be an effective and safe complementary therapy for CFS, which can be recommended to manage CFS. Because of the limited level of evidence in this review, further high-quality trials are still needed to confirm these findings.

\section{Introduction}

Myalgic encephalomyelitis/chronic fatigue syndrome (ME/ CFS) is a disabling clinical condition characterized by unexplained and persistent postexertional fatigue accompanied by a variety of symptoms related to cognitive, autonomous dysfunction, and immunological, including profound fatigue, orthostatic intolerance, unrefreshing sleep, and cognitive deficits [1]. It is estimated that the global average prevalence of CFS in adults is $0.65 \%$. When defined by the most commonly used cases, this proportion rises to $0.89 \%[2,3]$. Although CFS is not life-threatening, it seriously affects the patient's quality of life and causes a tremendous socioeconomic burden [4, 5]. According to the latest report from the Institute of Medicine of the United States, approximately 836,000 to 2.5 million Americans suffer from CFS [6], which incurs annual costs ranging from US\$1.8 to 24 billion per year [7].
To date, the pathogenesis of CFS is still unclear, and the Institute of Medicine (IOM) defines CFS as a complex multisystem neurological disease [8]. It is generally believed that the pathogenesis of CFS may be related to various factors, including brain structure and function, immune function, neuroendocrine response, viral infections, sleep architecture, and biopsychosocial models $[9,10]$. Since the etiology of CFS is unclear, the treatment of CFS mainly focuses on relieving symptoms [11]. However, there are currently no specific Food and Drug Administration (FDA)approved drugs for the treatment of CFS [12]. In addition, cognitive behavioral therapy (CBT) and graded exercise therapy (GET) are considered promising therapies for managing CFS [13]. However, recent studies have shown that the regulatory effects of CBT and GET are limited, and their effectiveness is still controversial [14-16]. Due to the limited overall therapeutic effects of CFS, some researchers 
have begun to turn their attention to complementary and alternative medicine (CAM).

Among various CAM therapies, moxibustion has been widely used in the management of various health conditions in China and has received widespread attention. As an ancient external treatment with a history of 2500 years, it involves using the heat of burning moxibustion to stimulate acupoints or specific surficial regions to relieve the symptoms of patients. According to the description in ancient Chinese literature, the therapeutic effect of moxibustion is related to improving the "weakness" symptoms of patients and preventing human diseases [17]. This makes moxibustion used as a complementary therapy for many diseases, including CFS.

Although the benefits of moxibustion for CFS have been widely reported [18], and some related systematic reviews have been conducted before, these systematic reviews have some limitations $[19,20]$. None of them evaluated the efficacy of using a single moxibustion. Therefore, we conducted a new systematic review to evaluate the efficacy of moxibustion alone in the treatment of CFS.

\section{Methods}

2.1. Data Source and Search Strategy. Seven online databases were searched from their inception to January 2021: PubMed, the Cochrane Library, EMBASE, CBM, CNKI, VIP, and Wanfang database. The search method used a combination of MeSH terms and free words, and the search terms were composed of intervention methods (moxibustion) and disease names (chronic fatigue symptoms). PubMed retrieval strategies are shown in Additional file 1. References listed in the included trials were also screened to identify potential trials.

2.2. Eligibility Criteria. Inclusion criteria were defined as follows: (1) the study was a randomized controlled trial (RCT); (2) subjects met the CFS diagnostic criteria established by the Centers for Disease Control and Prevention (for example, CDC 1994); (3) the intervention methods of the experimental group only included moxibustion, and there was no restriction on the type of moxibustion therapy; (4) the control group included active treatments (e.g., drugs, acupuncture, CBT, GET) or no treatment, and the drugs here do not contain Chinese herbal medicine; and (5) outcome indicators: (i) clinical efficacy (The clinical efficacy is mainly based on the standards established in the "Foreign Medical Sciences-Chinese Medicine fascicles," which is defined as effective when the main clinical symptoms and concurrent symptoms are improved by more than $1 / 3$ or $30 \%$; otherwise, it is considered invalid [21]. In addition, other clinical efficacy evaluation criteria with comparable definitions were also considered), (ii) fatigue severity (measured by validated scales such as fatigue scale-14 (FS14) and fatigue assessment instrument (FAI)), and (iii) adverse events (AEs). Exclusion criteria were defined as follows: (1) duplicate data; (2) non-RCT; (3) lack of definitive diagnostic criteria; (4) unusable data; and (5) the experimental group did not use moxibustion alone or the control group included moxibustion or Chinese herbal medicine.

2.3. Data Extraction. Two investigators independently browsed all the titles, abstracts, and full texts to screen eligible trials. Disagreements were resolved through discussion. Collected data included the following: study author, article publication date and location, and basic information of included trials (sample size, gender, age, intervention, and outcomes).

2.4. Study Quality Assessment. The quality assessment was performed independently by two investigators using the Cochrane risk of bias (ROB) tool [22], which included six items: the implementation of randomization, allocation concealment, blinding, the integrity of data, outcome reporting, and other biases. Each domain was graded three levels as low, high, or unclear ROB. Any inconsistencies were resolved by consulting a third investigator.

2.5. Data Synthesis and Analysis. RevMan 5.4 software was used for statistical analysis. The odds ratio (OR) with $95 \%$ confidence intervals (CI) were calculated for categorical data (Clinical efficacy), and weighted mean difference (WMD) with 95\% CIs were calculated for continuous variables (FS14 and FAI). Heterogeneity between trials was assessed by the $\chi^{2}$ test and $I^{2}$ test. If found homogenous $\left(I^{2} \leq 50 \%\right.$ and $P \geq 0.10$ ), then the fixed effect model was used; otherwise, the random-effects model was applied, and the sources of heterogeneity were explored using subgroup analysis or sensitivity analysis. We conducted subgroup analysis based on the differences in the control group and the type of moxibustion. Egger's test was used to analyze potential publication bias (more than 10 studies). In addition, the certainty of evidence was evaluated according to the GRADE system and was divided for each outcome index into four categories, including high, medium, low, and very low.

\section{Results}

3.1. Literature Search. 885 publications were retrieved from initial search. After deleting duplicates and reading the title, abstract, and full texts, finally, 15 trials [23-37] were included. The PRISMA flowchart of the literature search is shown in Figure 1.

3.2. Study Characteristics. Among the 15 RCTs, all trials were conducted in different provinces of China and the publication year was between 2007 and 2020. This study involved a total of 1030 CFS patients (520 in the moxibustion group, 510 in the control group). There were 10 trials $[25,29-37]$ that compared single moxibustion with acupuncture, and the remaining 5 trials $[23,24,26-28]$ compared single moxibustion with drugs. Table 1 shows the detailed information of all included RCTs. 

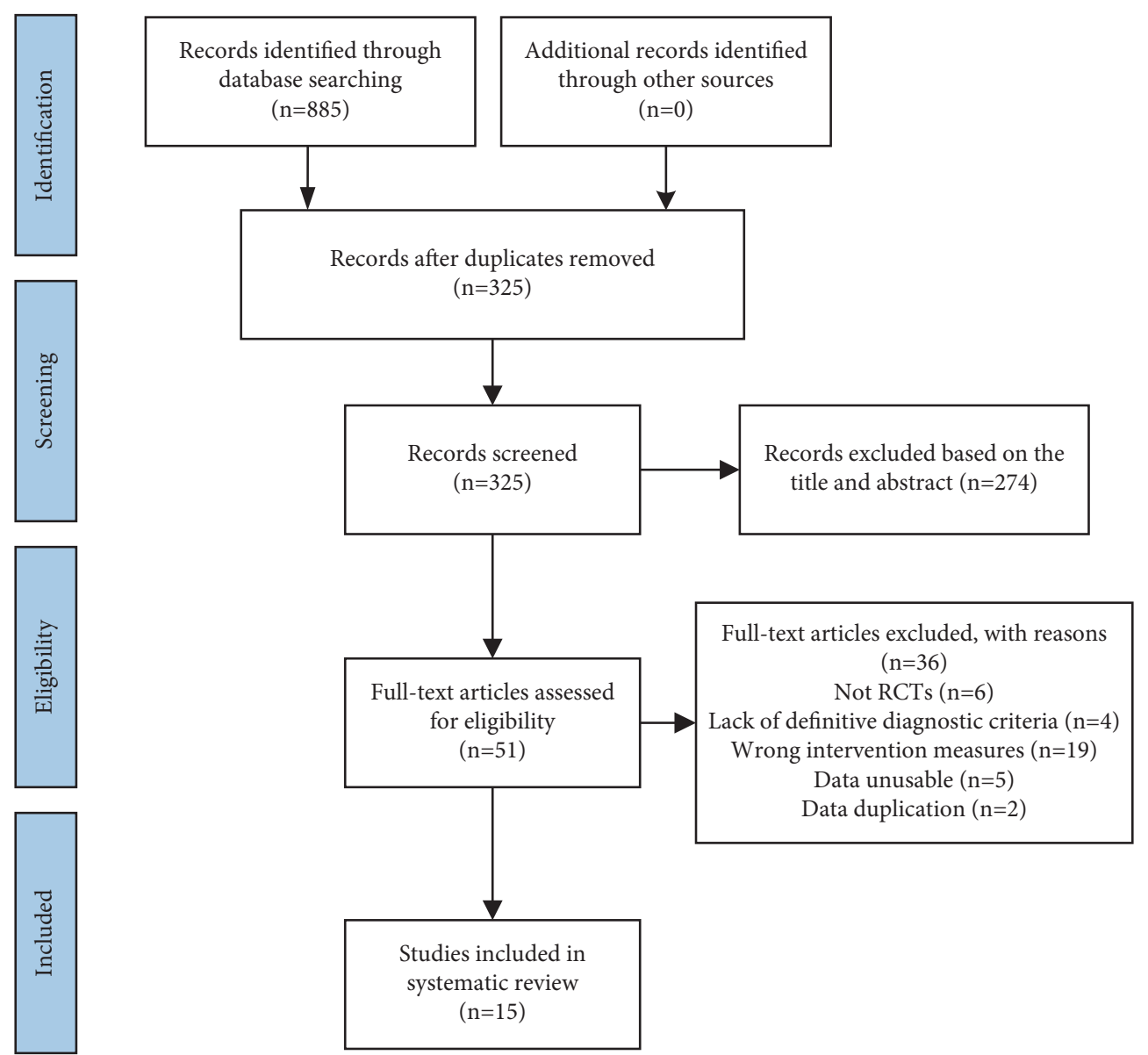

Figure 1: Flowchart of the study selection process.

TABLE 1: Characteristics of included studies.

\begin{tabular}{|c|c|c|c|c|c|c|c|}
\hline Study & Study location & $\begin{array}{l}\text { Sample } \\
\text { size } \\
\text { (male/ } \\
\text { female) }\end{array}$ & $\begin{array}{l}\text { Mean age } \\
\quad(\mathrm{SD})\end{array}$ & $\begin{array}{l}\text { Interventions } \\
\text { group }\end{array}$ & Control group & Treatment period & Outcomes \\
\hline $\begin{array}{l}\text { Guo } \\
\text { et al. } \\
(2007) \\
{[23]}\end{array}$ & Jiangsu, China & $\begin{array}{l}\text { T: } 14 / 19 \\
\text { C: } 12 / 20\end{array}$ & $\begin{array}{l}T: 36.01+6.74 \\
C: 35.12+7.30\end{array}$ & Moxibustion & Drug (fluoxetine) & $\begin{array}{c}\text { T: once a day for } 30 \\
\text { days, } 30 \text { min } \\
\text { C: once a day for } 30 \\
\text { days }\end{array}$ & CE \\
\hline $\begin{array}{l}\text { Chen } \\
\text { et al. } \\
\text { (2011) } \\
{[24]}\end{array}$ & $\begin{array}{l}\text { Guangdong, } \\
\text { China }\end{array}$ & $\begin{array}{l}\text { T: } 16 / 14 \\
\text { C: } 17 / 13\end{array}$ & $\begin{array}{l}\mathrm{T}: 35.12 \pm 4.17 \\
\mathrm{C}: 35.91 \pm 3.25\end{array}$ & Moxibustion & $\begin{array}{l}\text { Drug (vitamin } C+\text { vitamin } \\
\mathrm{E}+\text { trivitamins } \mathrm{B} \text { tablets) }\end{array}$ & $\begin{array}{l}\mathrm{T} \text { : once a day for } 28 \\
\text { days, } 10-20 \mathrm{~min} \\
\text { C: three times a day } \\
\text { for } 28 \text { days }\end{array}$ & CE \\
\hline $\begin{array}{l}\text { Lan } \\
(2011) \\
{[25]}\end{array}$ & $\begin{array}{l}\text { Guizhou, } \\
\text { China }\end{array}$ & $\begin{array}{l}\text { T: } 16 / 14 \\
\text { C: } 15 / 15\end{array}$ & $\begin{array}{c}\mathrm{T}: \\
30.70+8.801 \\
\mathrm{C}: \\
30.80+11.370\end{array}$ & Moxibustion & Acupuncture & $\begin{array}{l}\text { T: once a day, ten } \\
\text { days per period, one } \\
\text { days' break between } \\
\text { two periods, two } \\
\text { periods in total, } \\
20 \text { min } \\
\text { C: once a day, ten } \\
\text { days per period, one } \\
\text { days' break between } \\
\text { two periods, two } \\
\text { periods in total, } \\
20 \text { min }\end{array}$ & $\begin{array}{c}\text { CE, FAI, } \\
\text { AEs }\end{array}$ \\
\hline
\end{tabular}


TABle 1: Continued.

\begin{tabular}{|c|c|c|c|c|c|c|c|}
\hline Study & Study location & $\begin{array}{c}\text { Sample } \\
\text { size } \\
\text { (male/ } \\
\text { female) }\end{array}$ & $\begin{array}{l}\text { Mean age } \\
\quad(\mathrm{SD})\end{array}$ & $\begin{array}{l}\text { Interventions } \\
\text { group }\end{array}$ & Control group & Treatment period & Outcomes \\
\hline $\begin{array}{l}\text { Zou } \\
(2011) \\
{[26]}\end{array}$ & Jiangxi, China & $\begin{array}{l}\mathrm{T}: 15 / 15 \\
\mathrm{C}: 13 / 15\end{array}$ & $\begin{array}{c}\mathrm{T}: 34.67 \pm 3.24 \\
\mathrm{C}: \\
35.72 \pm 3.76\end{array}$ & Moxibustion & Drug (fluoxetine) & $\begin{array}{l}\text { T: once a day, eight } \\
\text { days per period, } \\
\text { three days' break } \\
\text { between two } \\
\text { periods, three } \\
\text { periods in total, } \\
15 \text { min } \\
\text { C: once a day for } 30 \\
\text { days }\end{array}$ & $\mathrm{CE}$ \\
\hline $\begin{array}{l}\text { Wang } \\
\text { et al. } \\
(2013) \\
{[27]}\end{array}$ & Anhui, China & $\begin{array}{l}\text { T: } 12 / 28 \\
\text { C: } 13 / 27\end{array}$ & $\begin{array}{l}\mathrm{T}: 39 \pm 6 \\
\mathrm{C}: 38 \pm 8\end{array}$ & $\begin{array}{l}\text { Thunder-fire } \\
\text { moxibustion }\end{array}$ & Drug (fluoxetine) & $\begin{array}{l}\text { T: once a day, ten } \\
\text { days per period, two } \\
\text { days' break between } \\
\text { two periods, two } \\
\text { periods in total } \\
\text { C: once a day for } 20 \\
\text { days }\end{array}$ & CE, AEs \\
\hline $\begin{array}{l}\text { Xiao } \\
\text { et al. } \\
(2014) \\
{[28]}\end{array}$ & $\begin{array}{l}\text { Guizhou, } \\
\text { China }\end{array}$ & $\begin{array}{l}\text { T: } 20 / 21 \\
\text { C: } 19 / 20\end{array}$ & $\begin{array}{l}\mathrm{T}: 40.2 \pm 8.2 \\
\mathrm{C}: 40.6 \pm 8.5\end{array}$ & Moxibustion & $\begin{array}{l}\text { Drug (vitamin } \mathrm{B} 1+\text { vitamin } \\
\text { B6 + oryzanol + paroxetine) }\end{array}$ & $\begin{array}{l}\text { T: once a day, ten } \\
\text { days per period, } \\
\text { three days' break } \\
\text { between two } \\
\text { periods, three } \\
\text { periods in total, } \\
15 \text { min } \\
\text { C: NR }\end{array}$ & $\begin{array}{l}\text { CE, FS-14, } \\
\text { AEs }\end{array}$ \\
\hline $\begin{array}{l}\text { Zhao } \\
(2014) \\
{[29]}\end{array}$ & $\begin{array}{l}\text { Heilongjiang, } \\
\text { China }\end{array}$ & $\begin{array}{l}\mathrm{T}: 10 / 20 \\
\mathrm{C}: 9 / 21\end{array}$ & $\begin{array}{c}\mathrm{T}: \\
40.80 \pm 6.599 \\
\mathrm{C}: \\
41.07 \pm 5.783\end{array}$ & $\begin{array}{l}\text { Ginger- } \\
\text { partitioned } \\
\text { moxibustion }\end{array}$ & Acupuncture & $\begin{array}{l}\text { T: once a day, five } \\
\text { times per week for } 4 \\
\text { weeks, } 50 \text { min } \\
\text { C: once a day, five } \\
\text { times per week for } 4 \\
\text { weeks, } 30 \text { min }\end{array}$ & CE, FS-14 \\
\hline $\begin{array}{l}\text { Zheng } \\
\text { et al. } \\
(2014) \\
{[30]}\end{array}$ & $\begin{array}{l}\text { Guangdong, } \\
\text { China }\end{array}$ & $\begin{array}{l}\mathrm{T}: 23 / 20 \\
\mathrm{C}: 21 / 22\end{array}$ & $\begin{array}{l}\mathrm{T}: 43.5 \pm 13.2 \\
\mathrm{C}: 42.6 \pm 12.9\end{array}$ & Moxibustion & Acupuncture & $\begin{array}{l}\text { T: once a day, seven } \\
\text { days per period, } \\
\text { three days' break } \\
\text { between two } \\
\text { periods, three } \\
\text { periods in total } \\
\text { C: once a day, seven } \\
\text { days per period, } \\
\text { three days' break } \\
\text { between two } \\
\text { periods, three } \\
\text { periods in total, } \\
30 \text { min }\end{array}$ & CE, AEs \\
\hline $\begin{array}{l}\text { Shi } \\
(2015) \\
{[31]}\end{array}$ & $\begin{array}{l}\text { Guangdong, } \\
\text { China }\end{array}$ & $\begin{array}{l}\text { T: } 8 / 22 \\
\text { C: } 9 / 20\end{array}$ & $\begin{array}{c}\mathrm{T}: \\
39.00 \pm 12.54 \\
\mathrm{C}: \\
41.62 \pm 11.70\end{array}$ & $\begin{array}{c}\text { Fu-Yang } \\
\text { moxibustion }\end{array}$ & Acupuncture & $\begin{array}{l}\text { T: twice a week for } \\
\text { six weeks } \\
\text { C: once a day, three } \\
\text { times per week for } \\
\text { six weeks }\end{array}$ & $\begin{array}{l}\text { CE, FS-14, } \\
\text { AEs }\end{array}$ \\
\hline
\end{tabular}


TABLE 1: Continued.

\begin{tabular}{|c|c|c|c|c|c|c|c|}
\hline Study & Study location & $\begin{array}{l}\text { Sample } \\
\text { size } \\
\text { (male/ } \\
\text { female) }\end{array}$ & $\begin{array}{l}\text { Mean age } \\
\text { (SD) }\end{array}$ & $\begin{array}{l}\text { Interventions } \\
\text { group }\end{array}$ & Control group & Treatment period & Outcomes \\
\hline $\begin{array}{l}\text { Tian } \\
\text { et al. } \\
(2015) \\
{[32]}\end{array}$ & Gansu, China & $\begin{array}{l}\text { T: } 24 / 12 \\
\text { C: } 16 / 20\end{array}$ & $\begin{array}{c}\mathrm{T}: 42 \pm 9 \\
\mathrm{C}: 42 \pm 10\end{array}$ & $\begin{array}{c}\text { Gaohuang } \\
\text { (BL43) } \\
\text { moxibustion }\end{array}$ & Acupuncture & $\begin{array}{l}\text { T: once a day, ten } \\
\text { days per period, two } \\
\text { days' break between } \\
\text { two periods, three } \\
\text { periods in total } \\
\text { C: once a day, ten } \\
\text { days per period, two } \\
\text { days' break between } \\
\text { two periods, three } \\
\text { periods in total, } \\
30 \text { min }\end{array}$ & $\begin{array}{c}\text { CE, FAI, } \\
\text { AEs }\end{array}$ \\
\hline $\begin{array}{l}\text { Hou } \\
\text { et al. } \\
(2017) \\
{[33]}\end{array}$ & $\begin{array}{c}\text { Shandong, } \\
\text { China }\end{array}$ & $\begin{array}{l}\text { T: } 16 / 12 \\
\text { C: } 14 / 12\end{array}$ & $\begin{array}{c}\mathrm{T}: 43.07 \pm 9.31 \\
\mathrm{C}: \\
45.62 \pm 9.92\end{array}$ & $\begin{array}{l}\text { Governor } \\
\text { moxibustion }\end{array}$ & Acupuncture & $\begin{array}{l}\text { T: twice a month for } \\
3 \text { months, } 6 \text { hours } \\
\text { C: once a day, four } \\
\text { times per week for } 3 \\
\text { months, } 30 \text { min }\end{array}$ & $\begin{array}{c}\text { CE, FS-14, } \\
\text { AEs }\end{array}$ \\
\hline $\begin{array}{l}\text { Sai } \\
(2018) \\
{[34]}\end{array}$ & $\begin{array}{l}\text { Shandong, } \\
\text { China }\end{array}$ & $\begin{array}{l}\text { T: } 17 / 15 \\
\text { C: } 13 / 17\end{array}$ & $\begin{array}{c}\mathrm{T}: 38.97 \pm 6.98 \\
\mathrm{C}: \\
37.73 \pm 6.26\end{array}$ & $\begin{array}{c}\text { Viscera } \\
\text { moxibustion }\end{array}$ & Acupuncture & $\begin{array}{l}\text { T: once a week for } 8 \\
\text { weeks, } 2 \text { hours } \\
\text { C: once a day, three } \\
\text { times per week for } 8 \\
\text { weeks, } 30 \mathrm{~min}\end{array}$ & $\mathrm{CE}$ \\
\hline $\begin{array}{l}\text { Luo } \\
\text { et al. } \\
(2019) \\
{[35]}\end{array}$ & $\begin{array}{c}\text { Guangdong, } \\
\text { China }\end{array}$ & $\begin{array}{l}\text { T: } 16 / 14 \\
\text { C: } 15 / 15\end{array}$ & $\begin{array}{l}\text { T: } 43 \pm 4 \\
\text { C: } 42 \pm 3\end{array}$ & $\begin{array}{c}\text { Fu-Yang } \\
\text { moxibustion }\end{array}$ & Acupuncture & $\begin{array}{l}\text { T: once every two } \\
\text { days for } 60 \text { days } \\
\text { C: once every two } \\
\text { days for } 60 \text { days, } \\
30 \text { min }\end{array}$ & $\begin{array}{c}\text { CE, FS-14, } \\
\text { AEs }\end{array}$ \\
\hline $\begin{array}{l}\text { Xu et al. } \\
(2019) \\
{[36]}\end{array}$ & Henan, China & $\begin{array}{l}\text { T: } 29 / 18 \\
\text { C: } 27 / 20\end{array}$ & $\begin{array}{l}\mathrm{T}: 41.5 \pm 5.3 \\
\mathrm{C}: 42.5 \pm 3.6\end{array}$ & $\begin{array}{l}\text { Governor } \\
\text { moxibustion }\end{array}$ & Acupuncture & $\begin{array}{l}\text { T: twice a month for } \\
3 \text { months, } 6 \text { hours } \\
\text { C: once a day, four } \\
\text { times per week for } 3 \\
\text { months, } 30 \mathrm{~min}\end{array}$ & CE, FS-14 \\
\hline $\begin{array}{l}\text { Wang } \\
\text { et al. } \\
(2020) \\
{[37]}\end{array}$ & Hunan, China & $\begin{array}{l}\text { T: } 13 / 27 \\
\text { C: } 15 / 25\end{array}$ & $\begin{array}{l}\mathrm{T}: 43.00 \pm 1.03 \\
\mathrm{C}: 43.00 \pm 1.17\end{array}$ & $\begin{array}{c}\text { Panlong } \\
\text { moxibustion }\end{array}$ & Acupuncture & $\begin{array}{c}\text { T: once a week for } 3 \\
\text { weeks, } 2 \text { hours } \\
\text { C: once a day, five } \\
\text { times per week for } 3 \\
\text { weeks, } 30 \text { min }\end{array}$ & $\begin{array}{c}\text { CE, FS-14, } \\
\text { FAI }\end{array}$ \\
\hline
\end{tabular}

AEs, adverse events; C, control group; CE, clinical efficacy; FAI, fatigue assessment instrument; FS-14, fatigue scale-14; NR: not reported; T, therapy group.

3.3. Risk of Bias. In all 15 RCTs, twelve trials [25, 27-37] clearly reported the implementation method of randomization, while in the other three trials $[23,24,26]$, the specific details of randomization were not mentioned. Only two trials $[25,35]$ mention the details of using allocation concealment. Due to the particularity of moxibustion operation, blinding the patient is not feasible. Only one study [32] mentioned the details of blinding, which implemented blinding in the outcome assessment process. Two trials $[31,34]$ mentioned dropouts without detail information of handling. No reporting bias was found among the included 15 RCTs. Since all RCTs were not registered in advance, other biases were classified as unclear. The Cochrane ROB assessment is shown in Figure 2.

3.4. Clinical Efficacy. All trials reported the effective rate of moxibustion in relieving CFS. No heterogeneity was found $\left(P=0.91, I^{2}=0 \%\right)$, and the fixed-effects model showed that moxibustion was better than the control group in improving the effective rate $(\mathrm{OR}=5.19, \quad 95 \% \mathrm{CI}=[3.58,7.53]$, $P<0.00001)$. The results of subgroup analysis also showed that moxibustion was better than acupuncture $(\mathrm{OR}=4.58$, $95 \% \mathrm{CI}=[2.85,7.35], P<0.00001)$ and drugs $(\mathrm{OR}=6.36$, $95 \% \mathrm{CI}=[3.48,11.59], P<0.00001)($ Figure 3$)$.

3.5. FS-14. Seven trials [28, 29, 31, 33, 35-37] evaluated fatigue severity by using FS-14. Analysis of data showed obvious heterogeneity $\left(P<0.00001, I^{2}=98 \%\right)$, and the random-effects model showed that moxibustion could further relieve SF-14 compared with the control group $\left(\mathrm{WMD}=-2.20,95 \% \quad \mathrm{CI}=\left[\begin{array}{ll}-3.16, & -1.24\end{array}\right], \quad P<0.00001\right)$. Subgroup analysis based on the type of control group also showed that moxibustion was better than acupuncture $(\mathrm{WMD}=-1.76,95 \% \mathrm{CI}=[-2.22,-1.30], P<0.00001)$ and drugs $(\mathrm{WMD}=-4.17,95 \% \mathrm{CI}=[-4.41,-3.93], P<0.00001)$. However, the heterogeneity of the meta-analysis of 


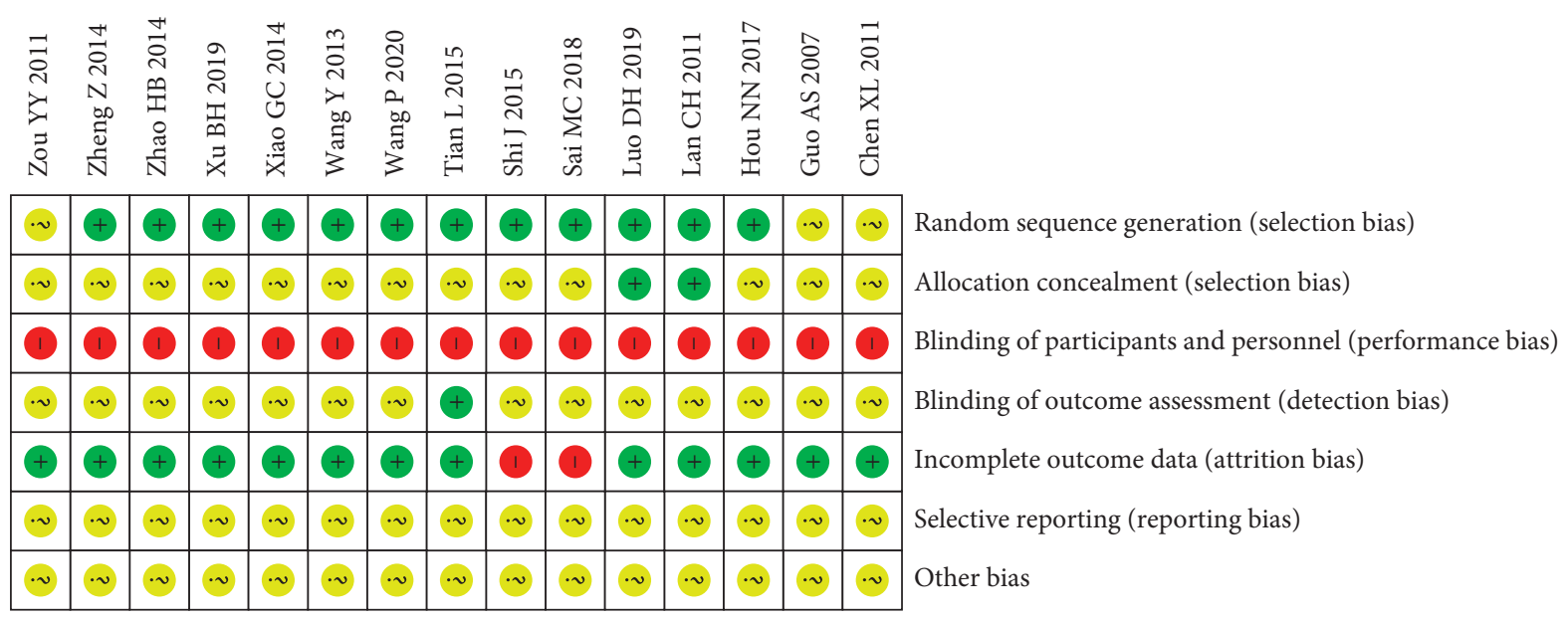

Figure 2: Potential risk of bias of each included study.

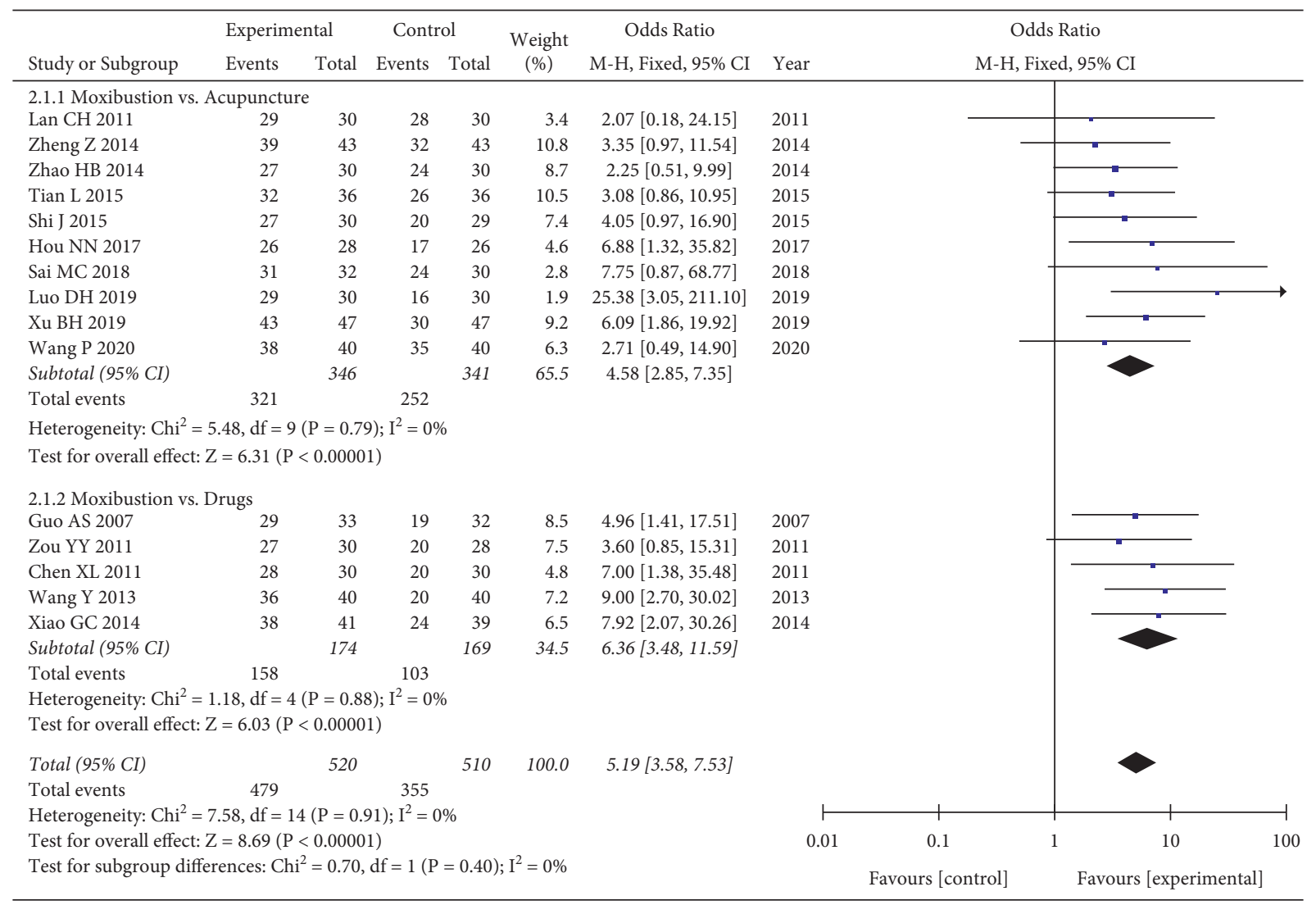

FIgURE 3: Forest plot of moxibustion on the total effective rate.

moxibustion versus acupuncture was still high. We conducted a subgroup analysis based on the type of moxibustion, and the results showed that the two subgroups Fu-Yang moxibustion $\left(P=0.53, I^{2}=0 \%\right)$ and governor moxibustion $\left(P=0.96, I^{2}=0 \%\right)$ did not find significant heterogeneity, and the four different types of moxibustion (Fu-Yang moxibustion, governor moxibustion, gingerpartitioned moxibustion, and Panlong moxibustion) can further relieve SF-14 compared with the acupuncture group, and Fu-Yang moxibustion ( $\mathrm{WMD}=-2.53,95 \%$
$\mathrm{CI}=[-3.31,-1.74], P<0.00001)$ seems to be better. The test of subgroup differences showed that the different control types $(P<0.00001)$ and moxibustion types $(P<0.00001)$ may cause heterogeneity (Figures 4 and 5$)$.

3.6. FAI. Three trials $[25,32,37]$ evaluated fatigue severity by using FAI scores. Since heterogeneity was found between the three RCTs $\left(P=0.03, I^{2}=70 \%\right)$, a random-effects model was used. Our pooled results showed that moxibustion could 


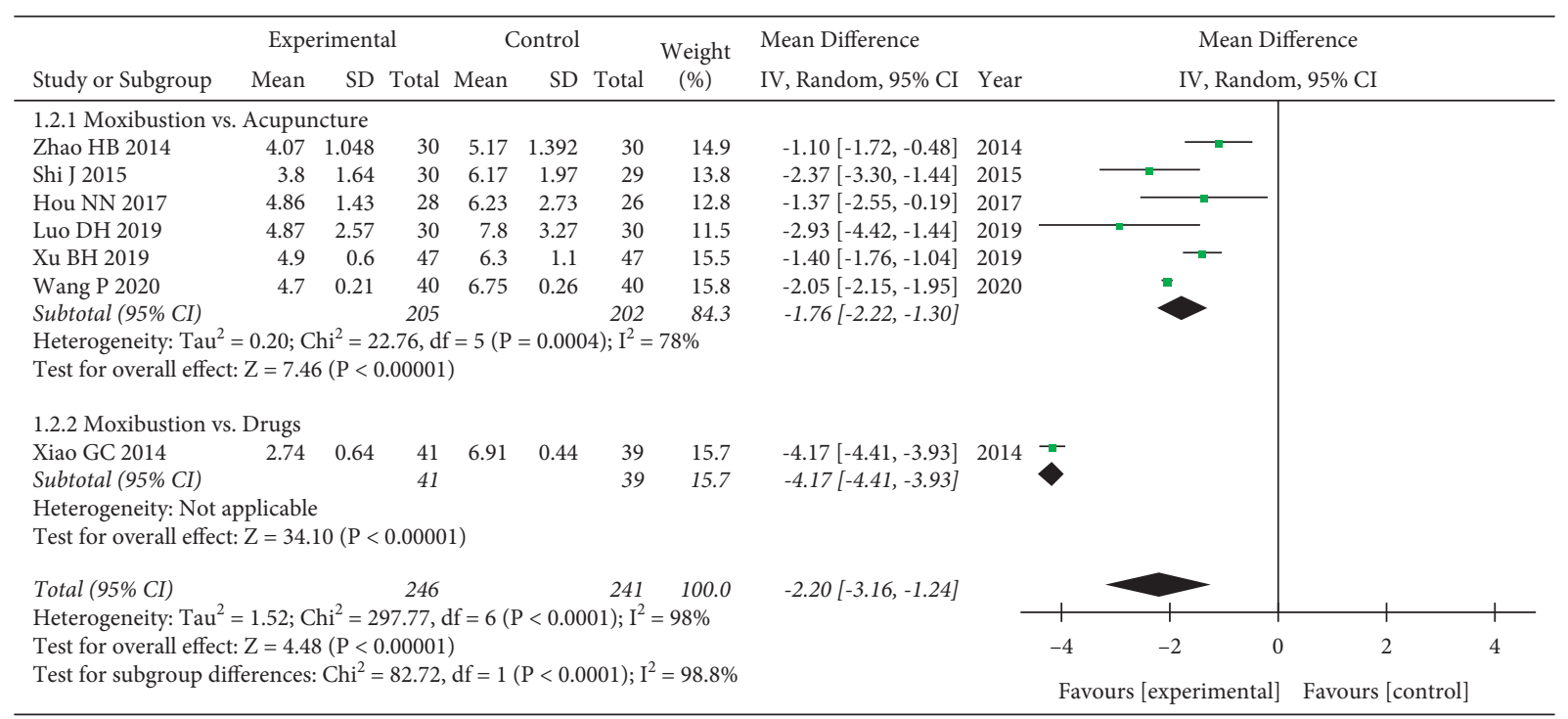

FIgURE 4: Forest plot of different control groups for FS-14.

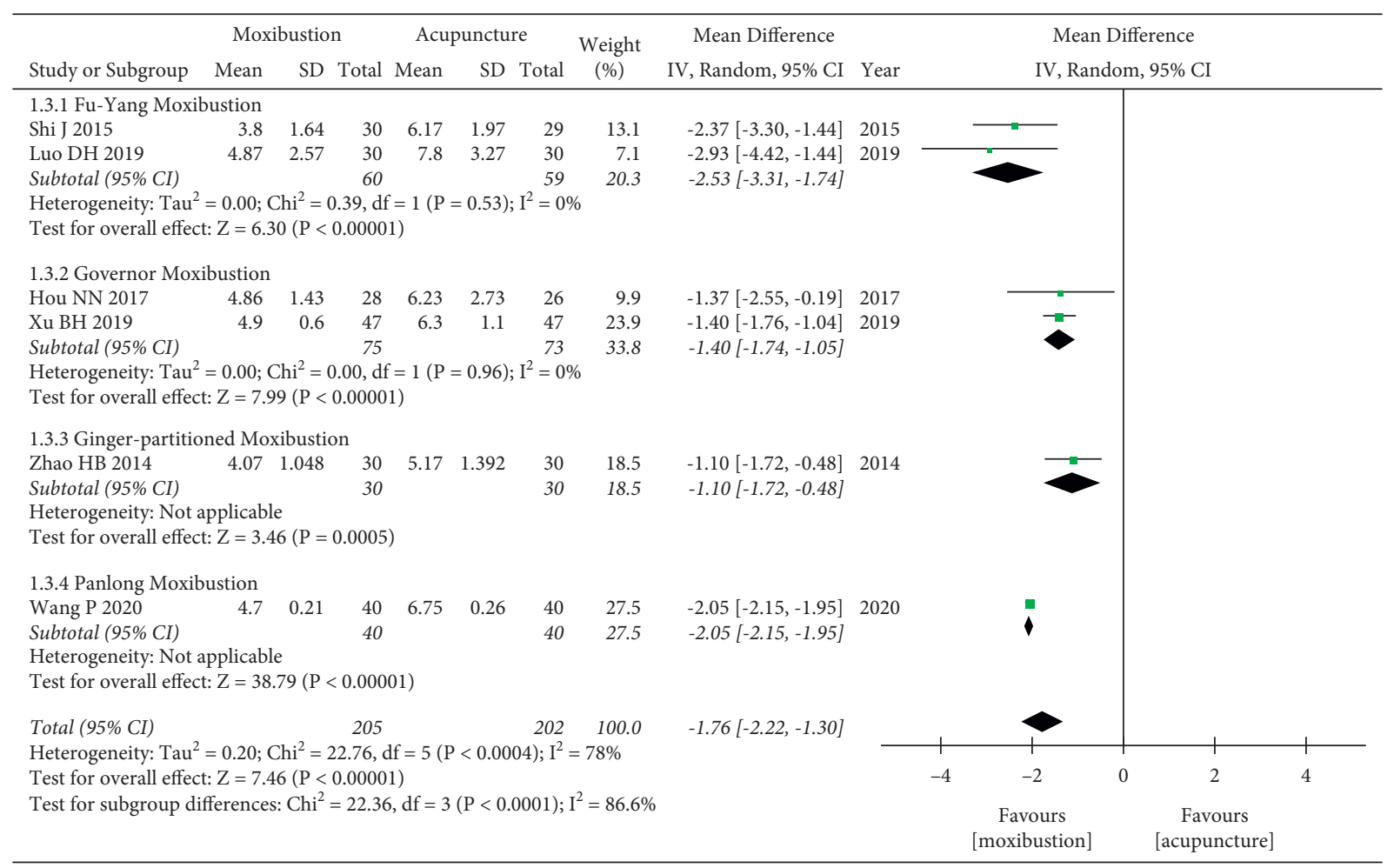

FIGURE 5: Forest plot of different moxibustion modalities for FS-14.

further improve the FAI score compared with acupuncture $\quad(\mathrm{WMD}=-16.36, \quad 95 \% \quad \mathrm{CI}=[-26.58, \quad-6.14]$, $P=0.002)$. Subgroup analysis based on the type of moxibustion also showed that Gaohuang (BL43) moxibustion and Panlong moxibustion were better than acupuncture. However, there was no statistically significant difference between routine moxibustion and acupuncture based on one study [25]. The test of subgroup differences indicated that the moxibustion types might lead to heterogeneity $(P=0.03)$ (Figure 6).
3.7. Safety Assessment. Eight trials [25, 27, 28, 30-33, 35] reported details of adverse events (AEs), and six $[27,28,30-33]$ of them reported no adverse events. Two trials $[25,35]$ reported moxibustion-related AEs, and both reported 1 case of mild scald. Two trials [25, 35] reported acupuncture-related AEs, one [25] reported 3 cases of dizziness during acupuncture, and one [35] reported 2 cases of local hematoma at the acupuncture site. The symptoms of the above-mentioned adverse events were relatively mild, and none of them affected the patient's follow-up treatment. 


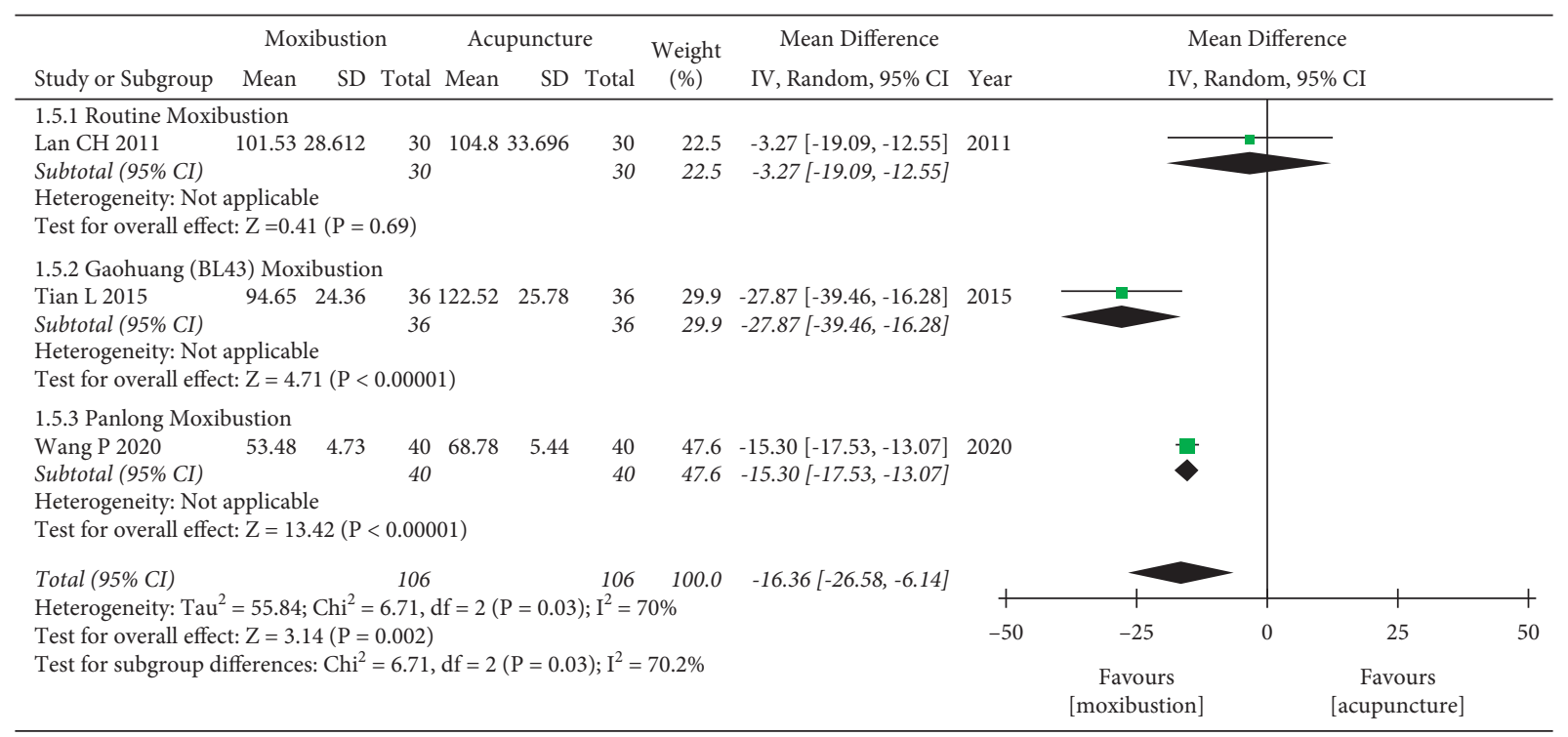

FIGURE 6: Forest plot of moxibustion on FAI.

3.8. Heterogeneity and Sensitivity Analysis. There was obvious heterogeneity in the comparison of moxibustion versus acupuncture on the FS-14 $\left(I^{2}=78 \%\right)$ and FAI score $\left(I^{2}=70 \%\right)$. We performed subgroup analysis based on the type of moxibustion, and the subgroup difference test showed that different modalities of moxibustion treatment may be the cause of the heterogeneity. Due to the small number of included studies for these two outcome indicators (less than 10 studies), we conducted sensitivity analysis by the conversion effect model. Sensitivity analysis indicated that the results of the meta-analysis were stable.

3.9. Publication Bias. We used Egger's test to analyze the publication bias of the total effective rate (more than 10 studies), and the results showed that the publication bias was not significant $(P=0.772)$ (Figure 7$)$.

3.10. Certainty of Evidence. The results of the GRADE analysis are shown in Table 2 . In general, in addition to the certainty of evidence for the clinical efficacy of moxibustion versus acupuncture, which was rated as "moderate," the other outcome indicators were rated as "low" or "very low." The main reasons leading to the decline in the certainty of the evidence for the outcome indicators include the methodological quality of most of the included studies was not high and the sample size was small, and the heterogeneity of some outcome indicators is obvious.

\section{Discussion}

To the best of our knowledge, this is the first meta-analysis to evaluate the efficacy of a single moxibustion treatment for CFS. In our current study, we included 15 RCTs that compared moxibustion with acupuncture (10 RCTs) and drugs (5 RCTs). Our pooled analysis indicated that

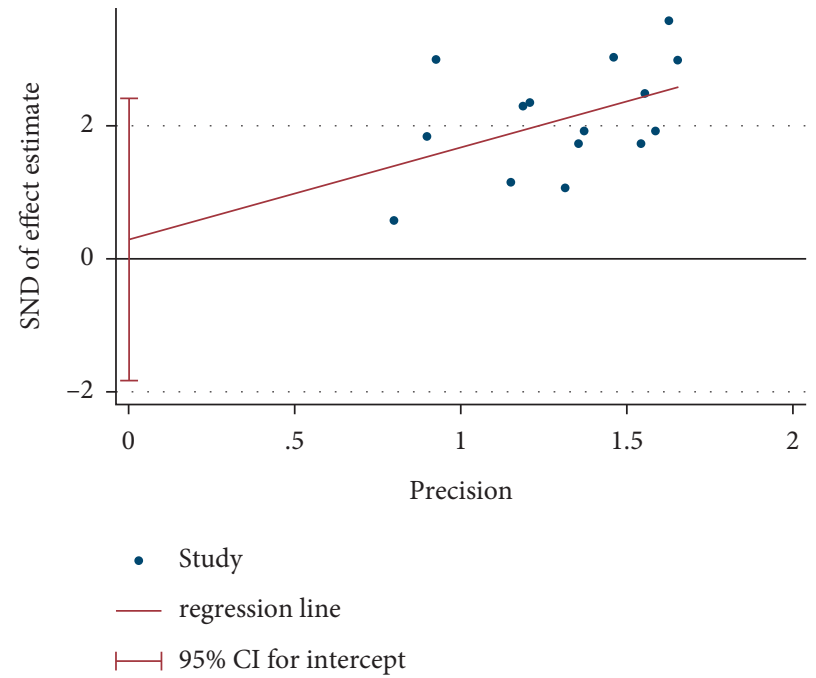

FIGURE 7: Egger's test plot of moxibustion on the total effective rate.

moxibustion was significantly better than acupuncture in relieving fatigue symptoms (FS-14 and FAI) and improving clinical efficacy $(P<0.05)$. In addition, compared with drugs, moxibustion has an advantage in improving the clinical efficacy and reducing the FS-14 score $(P<0.05)$. Although the clinical efficacy in this study was evaluated according to Chinese standards, this criterion involves the comprehensive evaluation of the main symptoms and accompanying symptoms of CFS patients. Therefore, we believe that the analysis conclusions of the clinical efficacy of this study are reliable. In addition, fatigue is one of the most important clinical symptoms of CFS. Both FS-14 and FAI clinically are internationally recognized measurement tools for evaluating fatigue symptoms, which can truly reflect the severity of fatigue $[38,39]$. Therefore, it is also credible to use FS-14 and FAI as outcome indicators for evaluating the efficacy of CFS. In terms of safety assessment, six studies reported no adverse events. Two studies reported adverse events of moxibustion, 
TABLE 2: GRADE certainty grading evaluation.

\begin{tabular}{|c|c|c|c|c|c|c|c|c|c|c|}
\hline \multirow[b]{2}{*}{$\begin{array}{l}\text { No. of } \\
\text { studies }\end{array}$} & \multicolumn{5}{|c|}{ Certainty assessment } & \multicolumn{3}{|c|}{ No. of patients } & \multirow{2}{*}{$\begin{array}{c}\text { Effect } \\
(95 \% \text { CI })\end{array}$} & \multirow[b]{2}{*}{ Certainty } \\
\hline & Design & $\begin{array}{c}\text { Risk of } \\
\text { bias }\end{array}$ & Inconsistency & Indirectness & Imprecision & $\begin{array}{l}\text { Publication } \\
\text { bias }\end{array}$ & $\begin{array}{l}\text { Experimental } \\
\text { group }\end{array}$ & $\begin{array}{l}\text { Control } \\
\text { group }\end{array}$ & & \\
\hline \multicolumn{11}{|c|}{ Clinical efficacy (moxibustion vs. acupuncture) } \\
\hline 10 & $\begin{array}{c}\text { Randomized } \\
\text { trials }\end{array}$ & Serious ${ }^{\mathrm{a}}$ & $\begin{array}{l}\text { No serious } \\
\text { inconsistency }\end{array}$ & $\begin{array}{l}\text { No serious } \\
\text { indirectness }\end{array}$ & $\begin{array}{l}\text { No serious } \\
\text { imprecision }\end{array}$ & None & $\begin{array}{l}321 / 346 \\
(92.8 \%)\end{array}$ & $\begin{array}{l}252 / 341 \\
(73.9 \%)\end{array}$ & $\begin{array}{c}\text { OR } 4.58 \\
(2.85 \\
7.35)\end{array}$ & $\begin{array}{c}\oplus \oplus \oplus \bigcirc \\
\text { Moderate }\end{array}$ \\
\hline \multicolumn{11}{|c|}{ FS-14 (moxibustion vs. acupuncture) } \\
\hline 6 & $\begin{array}{l}\text { Randomized } \\
\text { trials }\end{array}$ & Serious $^{\mathrm{a}}$ & Very serious ${ }^{b}$ & $\begin{array}{l}\text { No serious } \\
\text { inconsistency }\end{array}$ & $\begin{array}{l}\text { No serious } \\
\text { imprecision }\end{array}$ & None & 205 & 202 & $\begin{array}{c}\mathrm{MD} \\
-1.76 \\
(-2.22, \\
-1.30)\end{array}$ & $\begin{array}{c}\oplus 000 \\
\text { Very low }\end{array}$ \\
\hline \multicolumn{11}{|c|}{ FAI (moxibustion vs. acupuncture) } \\
\hline 3 & $\begin{array}{l}\text { Randomized } \\
\text { trials }\end{array}$ & Serious $^{\mathrm{a}}$ & Serious ${ }^{\mathrm{b}}$ & $\begin{array}{l}\text { No serious } \\
\text { inconsistency }\end{array}$ & Serious $^{c}$ & None & 106 & 106 & $\begin{array}{c}\mathrm{MD} \\
-16.36 \\
(-26.58 \\
-6.14)\end{array}$ & $\begin{array}{c}\oplus \bigcirc \bigcirc \bigcirc \\
\text { Very low }\end{array}$ \\
\hline \multicolumn{11}{|c|}{ Clinical efficacy (moxibustion vs. drugs) } \\
\hline 5 & $\begin{array}{l}\text { Randomized } \\
\text { trials }\end{array}$ & Serious $^{\mathrm{a}}$ & $\begin{array}{l}\text { No serious } \\
\text { inconsistency }\end{array}$ & $\begin{array}{l}\text { No serious } \\
\text { indirectness }\end{array}$ & Serious $^{c}$ & None & $\begin{array}{l}158 / 174 \\
(90.8 \%)\end{array}$ & $\begin{array}{l}103 / 169 \\
(60.9 \%)\end{array}$ & $\begin{array}{c}\text { OR } 6.39 \\
(3.48 \\
11.59)\end{array}$ & $\begin{array}{c}\oplus \oplus \bigcirc \bigcirc \\
\text { Low }\end{array}$ \\
\hline \multicolumn{11}{|c|}{ FS-14 (moxibustion vs. drugs) } \\
\hline 1 & $\begin{array}{l}\text { Randomized } \\
\text { trials }\end{array}$ & Serious $^{\mathrm{a}}$ & $\begin{array}{l}\text { No serious } \\
\text { inconsistency }\end{array}$ & $\begin{array}{l}\text { No serious } \\
\text { inconsistency }\end{array}$ & $\begin{array}{c}\text { Very } \\
\text { serious }^{c}\end{array}$ & None & 41 & 39 & $\begin{array}{c}\mathrm{MD} \\
-4.17 \\
(-4.41, \\
-3.93)\end{array}$ & $\begin{array}{c}\oplus \bigcirc \bigcirc \bigcirc \\
\text { Very low }\end{array}$ \\
\hline
\end{tabular}

${ }^{a}$ Risk of bias: most studies had a high risk of bias in methodology. ${ }^{b}$ Inconsistency: considerable heterogeneity. ${ }^{c}$ Imprecision: small sample size.

such as scald during moxibustion, but with mild symptoms. These adverse events can be effectively minimized by standardizing the operation steps of moxibustion [40,41]. Therefore, based on the findings of this study, we suggest that moxibustion might be an effective and safe complementary therapy for CFS. However, it cannot be ignored that the level of currently available evidence has been evaluated by the GRADE system as "moderate," "low," or "very low." This greatly weakens the reliability and impact of the evidence, which suggests that the interpretation of these positive results should be cautious. Therefore, the efficacy of moxibustion for CFS needs to be further explored.

Moxibustion is a traditional Chinese medicine method widely used in East Asia. The theoretical basis of moxibustion is the same as that of acupuncture, and they are guided by the theory of meridians and acupoints. However, since the application of moxibustion in clinics is not as extensive as acupuncture, the popularity and application of moxibustion in Western countries are not as good as acupuncture. In fact, like acupuncture, moxibustion also has the advantages of easy operation, safety, and economy $[40,42-44]$. TCM theory believes that moxibustion can regulate the balance of Qi and blood in the body by warming the meridians, unblocking the collaterals, and promoting the movement of Qi and blood, thereby restoring the body's Yang Qi vitality. This makes moxibustion widely used to treat diseases with "weakness" symptoms, including CFS $[32,45]$. In addition, modern research provides laboratorybased evidence that moxibustion can effectively regulate the behavior, immune function, and hypothalamic-pituitary- adrenal axis hormone levels of CFS model rats [46-48], thereby alleviating fatigue symptoms.

There were some limitations in this study. First, the methodological quality of most included trials in the Cochrane ROB assessment was not satisfactory. Only two trials implemented allocation concealment, and only one RCT reported blind details about the result evaluation. Second, all 15 included trials were from Chinese databases, which may cause language bias. Third, the sample size of most trials was small. Finally, the heterogeneity of the metaanalysis results (FS-14 and FAI) was high, which may be related to the moxibustion treatment plan of the experimental group (FS-14 and FAI) and the type of control group (FS-14). All of the above factors may limit the accuracy of the conclusions of this study.

\section{Conclusion}

Based on limited evidence, our research results show that moxibustion might be an effective and safe complementary therapy for CFS, especially in improving clinical efficacy and relieving fatigue symptoms. Due to the limited level of evidence, further high-quality RCTs are still needed to confirm the benefits of moxibustion for CFS.

\section{Data Availability}

This systematic review is a secondary analysis of the published RCTs data. All the study data can be accessed through the original articles listed in the "References" section. 


\section{Conflicts of Interest}

The authors declare no conflicts of interest.

\section{Authors' Contributions}

Jianyu You, Jing Ye, and Haiyan Li contributed equally to this work. Jianyu You and Wenguo Ye designed the research. Jianyu You, Haiyan Li, and Jing Ye collected, analyzed, and interpreted the data. Jianyu You wrote the draft of this paper. Wenguo Ye and Ensi Hong reviewed the manuscript. All authors approved the final manuscript.

\section{Acknowledgments}

This work was supported by the National Administration of Traditional Chinese Medicine Cultivation Discipline Construction-Science of Acupuncture and Moxibustion.

\section{Supplementary Materials}

Supplemental materials show the complete search process in PubMed. Our search terms include disease name (chronic fatigue symptoms) and intervention method (moxibustion). (Supplementary Materials)

\section{References}

[1] K. G. Brurberg, M. S. Fønhus, L. Larun, S. Flottorp, and K. Malterud, "Case definitions for chronic fatigue syndrome/ myalgic encephalomyelitis (CFS/ME): a systematic review," BMJ Open, vol. 4, no. 2, Article ID e003973, 2014.

[2] E.-J. Lim, Y.-C. Ahn, E.-S. Jang, S.-W. Lee, S.-H. Lee, and C.-G. Son, "Systematic review and meta-analysis of the prevalence of chronic fatigue syndrome/myalgic encephalomyelitis (CFS/ME)," Journal of Translational Medicine, vol. 18 , no. 1 , p. 100, 2020.

[3] A. Wright, P. L. Fisher, N. Baker, L. O’Rourke, and M. G. Cherry, "Perfectionism, depression and anxiety in chronic fatigue syndrome: a systematic review," Journal of Psychosomatic Research, vol. 140, Article ID 110322, 2021.

[4] K. J. Reynolds, S. D. Vernon, E. Bouchery, and W. C. Reeves, "The economic impact of chronic fatigue syndrome," Cost Effectiveness and Resource Allocation, vol. 2, no. 1, p. 4, 2004.

[5] S. M. Collin, I. J. Bakken, I. Nazareth, E. Crawley, and P. D. White, "Health care resource use by patients before and after a diagnosis of chronic fatigue syndrome (CFS/ME): a clinical practice research datalink study," BMC Family Practice, vol. 18, no. 1, p. 60, 2017.

[6] E. W. Clayton, "Beyond myalgic encephalomyelitis/chronic fatigue syndrome," Journal of the American Medical Association, vol. 313, no. 11, pp. 1101-1102, 2015.

[7] L. A. Jason, M. C. Benton, L. Valentine, A Johnson, and $S$ Torres-Harding, "The economic impact of ME/CFS: individual and societal costs," Dynamic Medicine: DM, vol. 7, p. 6, 2008.

[8] E. J. Lim and C. G. Son, "Prevalence of chronic fatigue syndrome (CFS) in Korea and Japan: a meta-analysis," Journal of Clinical Medicine, vol. 10, no. 15, 2021.

[9] N. Afari and D. Buchwald, "Chronic fatigue syndrome: a review," American Journal of Psychiatry, vol. 160, no. 2, pp. 221-236, 2003.
[10] G. Bjørklund, M. Dadar, L. Pivina, M. D Doşa, Y Semenova, and M Maes, "Environmental, neuro-immune, and neurooxidative stress interactions in chronic fatigue syndrome," Molecular Neurobiology, vol. 57, no. 11, pp. 4598-4607, 2020.

[11] P. Whiting, A.-M. Bagnall, A. J. Sowden, J. E. Cornell, C. D. Mulrow, and G. Ramírez, "Interventions for the treatment and management of chronic fatigue syndrome," Journal of the American Medical Association, vol. 286, no. 11, pp. 1360-1368, 2001.

[12] J. Castro-Marrero, N. Sáez-Francàs, D. Santillo, and J. Alegre, "Treatment and management of chronic fatigue syndrome/ myalgic encephalomyelitis: all roads lead to Rome," British Journal of Pharmacology, vol. 174, no. 5, pp. 345-369, 2017.

[13] E. B. Strand, L. Nacul, A. M. Mengshoel et al., "Myalgic encephalomyelitis/chronic fatigue Syndrome (ME/CFS): investigating care practices pointed out to disparities in diagnosis and treatment across European Union," PLoS One, vol. 14, no. 12, Article ID e0225995, 2019.

[14] K. J. Geraghty and C. Blease, "Cognitive behavioural therapy in the treatment of chronic fatigue syndrome: a narrative review on efficacy and informed consent," Journal of Health Psychology, vol. 23, no. 1, pp. 127-138, 2018.

[15] C. E. Wilshire, T. Kindlon, R. Courtney et al., "Rethinking the treatment of chronic fatigue syndrome-a reanalysis and evaluation of findings from a recent major trial of graded exercise and CBT," BMC Psychology, vol. 6, no. 1, p. 6, 2018.

[16] M. Vink and A. Vink-Niese, "Graded exercise therapy for myalgic encephalomyelitis/chronic fatigue syndrome is not effective and unsafe. Re-analysis of a Cochrane review," Health Psychology Open, vol. 5, no. 2, 2018.

[17] J. H. Chiu, "How does moxibustion possibly work?" Evidence Based Complementary and Alternative Medicine, vol. 2013, Article ID 198584, 8 pages, 2013.

[18] Y. F. Lin, J. F. Zhu, and Y. D. Chen, "Effect of ginger-separated moxibustion on fatigue, sleep quality and depression in patients with chronic fatigue syndrome: a randomized controlled trial," Zhongguo Zhen Jiu, vol. 40, no. 8, pp. 816-820, 2020.

[19] T. Wang, C. Xu, K. Pan, and H. Xiong, "Acupuncture and moxibustion for chronic fatigue syndrome in traditional Chinese medicine: a systematic review and meta-analysis," BMC Complementary and Alternative Medicine, vol. 17, no. 1, p. 163, 2017.

[20] T. Wang, Q. Zhang, X. Xue, and A Yeung, "A systematic review of acupuncture and moxibustion treatment for chronic fatigue syndrome in China," The American Journal of Chinese Medicine, vol. 36, no. 1, pp. 1-24, 2008.

[21] Q. Liu, "The curative effect standard of TCM diagnosis and treatment of chronic fatigue syndrome," Foreign Med Fascicle Chin Med, vol. 15, no. 6, p. 15, 1993.

[22] J. P. T. Higgins, D. G. Altman, P. C. Gotzsche et al., "The Cochrane Collaboration's tool for assessing risk of bias in randomised trials," BMJ, vol. 343, no. 2, p. d5928, 2011.

[23] A. S. Guo, Y. H. Gu, and H. Z. Jin, "A comparative study on the efficacy of moxibustion in the treatment of chronic fatigue syndrome," Journal of Liaoning University of Traditional Chinese Medicine, vol. 9, no. 4, pp. 29-30, 2007.

[24] X. L. Chen, K. Xu, and J. Zhou, "Clinical observation on the treatment of chronic fatigue syndrome with moxibustion at Guanyuan (CV 6) and Qihai (CV 6)," Journal of New Chinese Medicine, vol. 43, no. 2, pp. 109-110, 2011.

[25] C. H. Lan, Comparative Observation on the Clinical Efficacy of Moxibustion and Acupuncture at Wu Zang Back Shu Points for 
Patients with Chronic Fatigue Syndrome, Guiyang College of Traditional Chinese Medicine, Guiyang, China, 2011.

[26] Y. Y. Zou, "A clinical randomized controlled study of moxibustion at shenque (CV 8) in treating chronic fatigue syndrome," Journal of Yichun College, vol. 33, no. 8, p. 94+166, 2011.

[27] Y. Wang, W. Xiao, and J. Wang, "Therapeutic observation on thunder-fire moxibustion for chronic fatigue syndrome," Shanghai Journal of Acupuncture and Moxibustion, vol. 32, no. 10, pp. 827-828, 2013.

[28] G. C. Xiao, J. Cui, and F. L. Xiong, "Observation of the clinical efficacy on 41 cases of chronic fatigue syndrome treated with moxibustion at back-shu points of five zang organs," World Journal of Integrated Traditional and Western Medicine, vol. 9, no. 11, pp. 1218-1221, 2014.

[29] H. B. Zhao, Clinical Observation Ginger Partition Moxibustion Therapy Spleen and Kidney Yang Deficiency Chronic Fatigue Syndrome, Heilongjiang University of Chinese Medicine, Harbin, China, 2014.

[30] Z. Zheng, S. Wen, and Z. J. Cai, "Functional health moxibustion treatment of chronic fatigue syndrome random parallel control study," Journal of Practical Traditional Chinese Internal Medicine, vol. 28, no. 6, pp. 59-61, 2014.

[31] J. Shi, Clinical Study on Fu Yang Moxibustion in Treating Chronic Fatigue Syndrome of Spleen and Kidney Yang Deficiency Type, Guangzhou University of Chinese Medicine, Guangzhou, China, 2015.

[32] L. Tian, J. Wang, and C. Luo, "Moxibustion at Gaohuang (BL 43) for chronic fatigue syndrome: a randomized controlled trial," Zhongguo Zhen Jiu, vol. 35, no. 11, pp. 1127-1130, 2015.

[33] N. N. Hou, A. L. Li, and L. P. Teng, "Effects of Governor moxibustion on chronic fatigue syndrome with yang deficiency of spleen-kidney syndrome," Hebei Journal of Traditional Chinese Medicine, vol. 39, no. 8, pp. 1235-1238+1242, 2017.

[34] M. C. Sai, Observation of Clinical Effect of the Viscera Moxibustion on Chronic Fatigue Syndrome, Shandong University of Traditional Chinese Medicine, Jinan, China, 2018.

[35] D. H. Luo, Q. Huang, and Y. M. Wang, "Clinical observation of treatment of chronic fatigue syndrome with spleen and kidney yang deficiency type with fu-yang moxibustion," Asia-Pacific Traditional Medicine, vol. 15, no. 2, pp. 126-128, 2019.

[36] B. H. Xu, T. K. Liu, and G. Z. Zheng, "Observation on the clinical effect of governor moxibustion on patients with chronic fatigue syndrome of spleen and kidney yang deficiency," Medical Journal of Chinese People's Health, vol. 31, no. 5, pp. 89-90, 2019.

[37] P. Wang, W. H. Xu, and D. Zhou, "Clinical effect of Panlong moxibustion on chronic fatigue syndrome and its influence on CRH,ACTH and CORT," Medical Innovation of China, vol. 17, no. 21, pp. 74-77, 2020.

[38] T. Chalder, G. Berelowitz, T. Pawlikowska et al., "Development of a fatigue scale," Journal of Psychosomatic Research, vol. 37, no. 2, pp. 147-153, 1993.

[39] J. E. Schwartz, L. Jandorf, and L. B. Krupp, "The measurement of fatigue: a new instrument," Journal of Psychosomatic Research, vol. 37, no. 7, pp. 753-762, 1993.

[40] J. Xu, H. Deng, and X. Shen, "Safety of moxibustion: a systematic review of case reports," Evidence Based Complementary and Alternative Medicine, vol. 2014, Article ID 783704, 10 pages, 2014.

[41] D. Y. Xie, Y. Q. Chen, and Q. L. Li, "Experience of CHEN Rixin's clinical safety operation of heat-sensitive moxibustion,"
China Journal of Traditional Chinese Medicine and Pharmacy, vol. 35, no. 4, pp. 1869-1871, 2020.

[42] Z. Huang, Z. Qin, and Q. Yao, "Moxibustion for chemotherapy-induced nausea and vomiting: a systematic review and meta-analysis," Evidence Based Complementry and Alternative Medicine, vol. 2017, Article ID 9854893, 11 pages, 2017.

[43] J. You, H. Li, D. Xie, R Chen, and M Chen, “Acupuncture for chronic pain-related depression: a systematic review and meta-analysis," Pain Research \& Management, vol. 2021, Article ID 6617075, 10 pages, 2021.

[44] F. Liu, J. Y. You, and Q. Li, "Acupuncture for chronic painrelated insomnia: a systematic review and meta-analysis," Evidence Based Complementary and Alternative Medicine, vol. 2019, Article ID 5381028, 10 pages, 2019.

[45] Y. F. Lin, X. Q. Jin, and J. F. Zhu, "Ginger-separated moxibustion for chronic fatigue syndrome and its effect on intestinal flora," Zhongguo Zhen Jiu, vol. 41, no. 3, pp. 269-274, 2021.

[46] Y. M. Lin, G. H. Jiang, and Y. X. Li, "Effects of moxibustion at Qihai and Guanyuan acupoints on behavior and immune systems of chronic fatigue rats," Shanghai Journal of Traditional Chinese Medicine, vol. 51, no. 6, pp. 93-96, 2017.

[47] J. Zeng, J. Huang, and M. Z. Lu, "The effect of moxibustion on immune function in chronic fatigue rats," Journal of Clinical Acupuncture and Moxibustion, vol. 27, no. 9, pp. 56-59, 2011.

[48] L. Zhao and G. H. Jiang, "Effects of moxibustion on behavior and hormone levels of hypothalamus-pituitary-adrenergic Axis of the model rat with chronic fatigue syndrome," Shandong Journal of Traditional Chinese Medicine, vol. 33, no. 4, pp. 301-303, 2014. 